\title{
Screening of Different Hevea brasiliensis Clones Based on the Reaction to Phytophthora Bark Rot
}

\author{
Silva M.K.R. ${ }^{1 *}$, Fernando T.H.P.S. ${ }^{1}$, Tennakoon B.I. ${ }^{1}$ \\ ${ }^{1}$ Rubber Research Institute, Sri Lanka \\ *keshanisilva@yahoo.com
}

\begin{abstract}
Disease conditions caused by Phytophthora species are common on rubber (Hevea brasiliensis) in all rubber-growing countries. Bark rot is the most economically damaging disease of the tapping panel of the rubber tree, leading to the cessation of tapping during the monsoon months in rubber plantations. To overcome this situation, the disease screening programs aiming disease resistant/tolerant clones are continually carried out. The current study attempted to evaluate the reaction of different clones of $H$. brasiliensis against the Phytophthora bark rot in order to recommend a suitable planting material for the industry. Forty clones of $H$. brasiliensis were screened at the bud wood nursery of Kuruwita substation of Rubber Research Institute of Sri Lanka during South West monsoon, 2014. Each clone consisted ten bud wood plants and in each bud wood plant, three branches were used for the inoculation. These plants of different clones were artificially inoculated with a standard spore suspension of Phytophthora meadii. This was prepared by scraping the sporangia on the surface of culture plates into sterile distilled water and the final concentration was adjusted to $1 \times 10^{4}$ spores per ml. At the inoculation, the bark of the selected branches was removed with a cork borer and the wood was exposed. A sterile absorbent cotton wool plug saturated with 2 $\mathrm{ml}$ of the zoospore suspension was placed on the exposed wood of the plant. The cotton wool plugs were taken in sterile Petri dishes to the experimental site and a freshly-prepared zoospore suspension was used. As the control, in each of the bud wood plant tested, one branch was inoculated with a cotton wool plug with sterile distill water. After the inoculation, the inoculated portions of the branch were sealed off with budding tape in such a manner to ensure aeration. Four weeks after the inoculation, the exposed lesions were traced on to tracing papers, after removing the bark and the area under the lesions were measured with a plannimeter. The area under the lesion was assumed to be inversely proportional to the resistance level of the relevant rubber clones towards the $P$. meadii infection. The area of the lesion resulted after each treatment was subjected to analysis of variance in SAS statistical software. The results of the trial carried out suggest the possibility of categorizing the screened clones into three clusters. The clones RRISL 222, RRISL 220, RRISL 208, RRISL 219, RRIM 600, RRIC 102, RRIM 717 and PB 235 are among the most resistant clones while the clones, PB 255, RRISL 206, RRISL 225, RRISL 201, RRIC 130, RRISL 211, RRISL 205 and RRIC 131 are among the most susceptible clones against Phytophthora bark rot. Therefore, it can be concluded that, the screened clones were showing differential reaction to the Phytophthora bark rot under bud wood nursery conditions.
\end{abstract}

Keywords: Phytophthora bark rot, Hevea brasiliensis, Clonal screening

Proceedings of the $22^{\text {nd }}$ International Forestry and Environment Symposium 2017 of the Department of Forestry and Environmental Science, University of Sri Jayewardenepura, Sri Lanka 